\title{
A informação e o entorno digital: competências e habilidades
}

\section{do profissional da informação}

\author{
Francisco Carlos Paletta \\ Universidade de São Paulo, Escola de Comunicações e Artes, São Paulo, SP, Brasil \\ fcpaletta@usp.br \\ José Antonio Moreiro-González \\ Universidad Carlos III, Departamento de Biblioteconomía y Documentación, Madrid, España \\ jamore@bib.uc3m.es
}

DOI: https://doi.org/10.26512/rici.v13.n1.2020.29558

Recebido/Recibido/Received: 2020-01-15

Aceitado/Aceptado/Accepted: 2020-02-11

Resumo: Inovação, ciência e tecnologia são conceitos presentes em todas as áreas do conhecimento e do processo produtivo global. A inovação é uma vantagem competitiva que deve ser desenvolvida e adotada e que não pode estar dissociada de ciência e tecnologia. O objetivo deste trabalho é estudar as competências e habilidades do profissional da informação no entorno digital. A metodologia da pesquisa é do nível descritivo em fonte secundária, por meio de levantamento bibliográfico, análise e conceitos, que tem como objetivo proporcionar maior familiaridade com o assunto e torná-lo mais explícito. Como resultados apresenta reflexão sobre o papel da inovação nos processos de formação profissional no entorno digital e seus impactos na empregabilidade global. Apresenta como conclusão o reconhecimento do papel da ciência, da tecnologia e da inovação na competitividade do setor produtivo bem como as estratégias de apoio, o que inclui programas de conscientização para as diferentes partes envolvidas com o processo de inovação; programas para a difusão dos conceitos de inovação nas comunidades interessadas em atividades produtivas, de modo que a ciência e a tecnologia possa ser melhor utilizadas; capacidade de resposta dos centros de pesquisa em ciência e tecnologia às demandas do setor produtivo; medição de resultados mediante sistemas de intercâmbio, de retroalimentação e monitoração; e apropriação, ou seja, a capacidade das organizações não somente de usar, mas também de contribuir para o aperfeiçoamento das tecnologias transferidas.

Palavras-chave: entorno digital. competência digital. habilidades digitais. profissional da informação. inovação. transformação digital.

Information and the digital environment: competencies and skills of the information professional Abstract: Innovation, science and technology are concepts present in all areas of knowledge and the global production process. Innovation is a competitive advantage that must be developed and adopted and cannot be dissociated from science and technology. The objective of this work is to study the competences and skills of the information professional in the digital environment. The methodology of the research is of the descriptive level in secondary source, by means of bibliographical survey, analysis and concepts, which aims to provide greater familiarity with the subject and make it more explicit. The results present a reflection on the role of innovation in professional training processes in the digital environment and its impacts on global employability. It concludes by recognizing the role of science, technology and innovation in the competitiveness of the productive sector, as well as support strategies, which includes awareness programs for the different parties involved in the innovation process; programs for the dissemination of innovation concepts in communities interested in productive activities, so that science and technology can be better used; responsiveness of science and technology research centers to the demands of the productive sector; measurement of results through exchange, 
feedback and monitoring systems; and ownership, i.e. the ability of organizations not only to use, but also to contribute to the improvement of transferred technologies.

Keywords: digital environment. digital skills. digital abilities. information professional. innovation. digital transformation.

Información y entorno digital: competencias y habilidades del profesional de la información.

Resumen: La innovación, la ciencia y la tecnología son conceptos presentes en todas las áreas del conocimiento y del proceso de producción global. La innovación es una ventaja competitiva que debe desarrollarse y adaptarse y no puede disociarse de la ciencia y la tecnología. El objetivo de este trabajo es estudiar las competencias y habilidades del profesional de la información en el entorno digital. La metodología de la investigación es de nivel descriptivo en fuente secundaria, mediante el estudio bibliográfico, el análisis y los conceptos, que tiene por objeto proporcionar una mayor familiaridad con el tema y hacerlo más explícito. Los resultados presentan una reflexión sobre el papel de la innovación en los procesos de formación profesional en el entorno digital y sus repercusiones en la empleabilidad mundial. Concluye reconociendo el papel de la ciencia, la tecnología y la innovación en la competitividad del sector productivo, así como las estrategias de apoyo, que incluyen programas de sensibilización para las diferentes partes involucradas en el proceso de innovación; programas de difusión de conceptos de innovación en las comunidades interesadas en las actividades productivas, para que la ciencia y la tecnología puedan ser mejor utilizadas; la capacidad de respuesta de los centros de investigación científica y tecnológica a las demandas del sector productivo; la medición de los resultados a través de sistemas de intercambio, retroalimentación y supervisión; y la propiedad, es decir, la capacidad de las organizaciones no sólo de utilizar sino también de contribuir al mejoramiento de las tecnologías transferidas.

Palabras-clave: Entorno Digital. Habilidades digitales. Profesional de la Información. Innovación. Transformación digital.

\section{Introdução}

A Era Digital e a Transformação 4.0 estão alicerçadas em uma cultura de valorização do conhecimento, da tecnologia, da inovação, da criatividade, da mobilidade e remete-nos à importância da conectividade como elemento de promoção da democratização do acesso à informação.

Na sociedade moderna, a informação tem papel estratégico para a definição de estratégias de competitividade global, situação que exige propostas de formação profissional que atendam às demandas do mercado de trabalho no entorno digital.

Além de uma excelente formação técnica, as organizações necessitam de profissionais com capacidade de gestão, criatividade, empreendedorismo, comunicação e liderança. (MATTOS, 2013)

O advento da rápida obsolescência do conhecimento também reflete a necessidade de um profissional com uma visão holística, com habilidades gerenciais, metodológicas, culturais e sistêmicas.

A competitividade global impõe um novo perfil de profissional da informação, que tem como desafio equilibrar as habilidades de uma sólida formação técnica com a capacidade de gestão dos processos produtivos com foco na competitividade internacional.

Atenta a esse novo contexto tecnológico, os Cursos de Biblioteconomia e Ciência da Informação precisam desenvolver currículos que proporcionem uma formação técnica 
alinhada com os desafios do mercado global sem deixar de se preocupar com a formação cultural e humanística de seus alunos visando à formação de líderes tecnológicos que possam contribuir ativamente para com o desenvolvimento sustentável, geração de riqueza e distribuição de renda.

Fator relevante neste processo de formação de profissionais com competências globalizadas está na construção de um corpo docente que comtemple a necessidade de mestres e doutores bem como de especialistas que ocupem posições ativas e estratégicas no mercado de trabalho, o que permite enriquecer o ambiente acadêmico com novas abordagens, tecnologias e tendências. As aulas, tanto teóricas quanto práticas devem fazer uso de modernos recursos computacionais que permitam a reprodução de ambiente de pesquisa, desenvolvimento e produção levando o aluno e professor a vivenciar a realidade competitiva em que as organizações estão inseridas. (OCDE, 2017)

\section{Ciência da Informação e a formação profissional}

Para enfrentarmos a competitividade internacional, precisamos redimensionar o valor estratégico da ciência e compreender que ainda há um imenso trabalho a realizar na construção de um projeto inovador, moderno e atual de formação dos profissionais da informação, Figura 1, no entorno digital.

Figura 1 Estratégia de Formação do Profissional da Informação

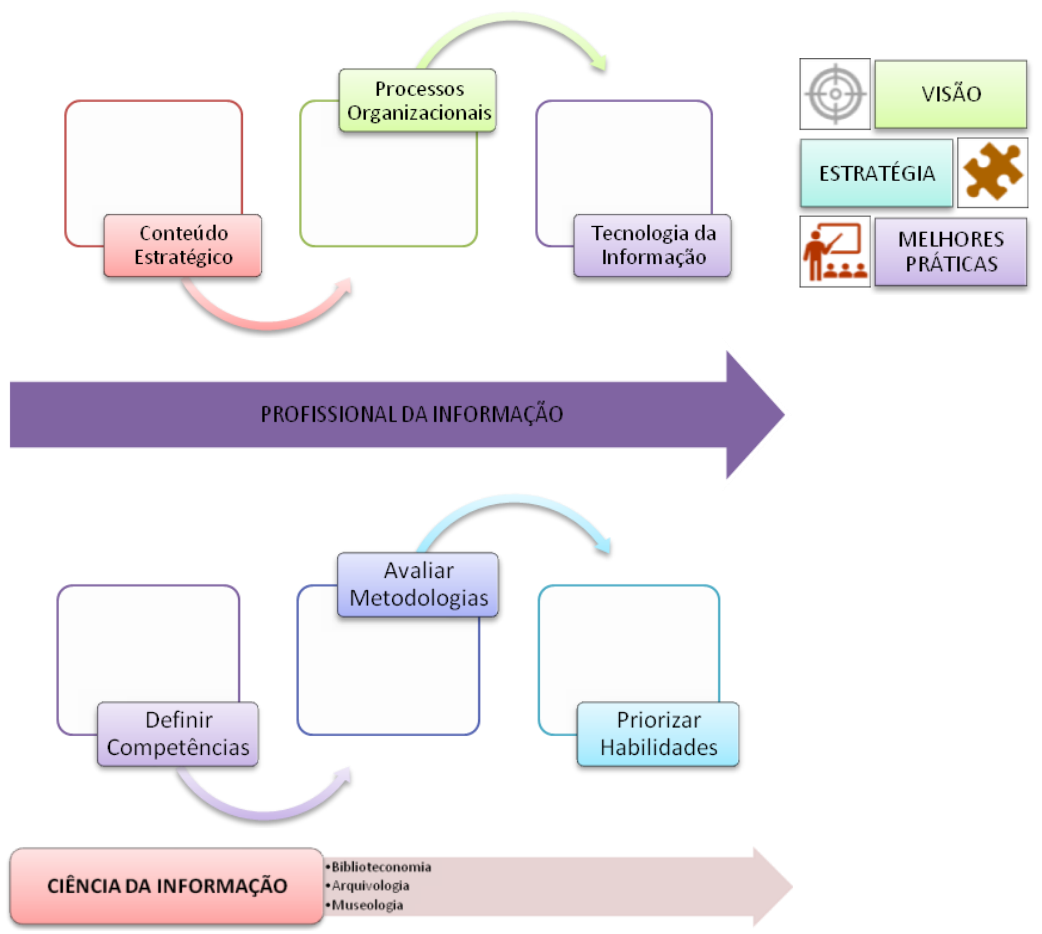

Fonte: o autor. 
Podemos estabelecer uma conexão entre a formação de recursos humanos, a ciência e o crescimento econômico sustentável. Uma que nos interessa sobremaneira, trata da modernização dos processos educacionais. Não basta mais garantir a boa formação técnica dos estudantes, é preciso desenvolver novas habilidades exigidas pela complexidade do mercado de trabalho global.

Nesse contexto de mudanças cada vez mais dinâmicas, os conhecimentos tornam-se obsoletos rapidamente. É preciso pensar em uma qualificação holística, valorizando habilidades de gestão, comunicação, liderança, empreendedorismo, criatividade, inovação, culturais, multidisciplinares e sistêmicas - todas destacadas na economia do conhecimento. (AMORÓS, 2014).

Para bem pensar hoje o ofício da educação, é preciso compreender e valorizar a complexidade do mundo contemporâneo. Além de uma competência técnica específica, no caso da Ciência da Informação, absolutamente indispensável, observamos a demanda por habilidades culturais, socioambientais, inter-ultra-multidisciplinares. Educar o profissional da informação para o século XXI é equilibrar o binômio especialista - em sua dimensão técnica versus generalista - de caráter multidisciplinar.

\section{Inovação: conexões com a Ciência da Informação}

A incorporação da inteligência nos modos de produção e a consequente Transformação 4.0 vêm recebendo destaque e ganhou novas roupagens nas últimas décadas: inovação e empreendedorismo.

Para se tirar vantagens das oportunidades apresentadas pelas novas tecnologias, são necessárias a criação de instituições e mecanismos que permitam a atualização e modernização dos modelos de gestão e consequentemente a definição de novas competências - Digital Literacy, do profissional da informação.

O conhecimento, que sempre foi um dos principais insumos para a geração de riqueza e bem-estar social, passou a ser reconhecido como tal a partir da revolução da informação trazida pela Internet. A capacidade de uma nação de gerar conhecimento e converter conhecimento em riqueza e desenvolvimento social depende da ação de alguns agentes institucionais geradores e aplicadores de conhecimento. Os principais agentes que compõem um sistema nacional de geração e apropriação de conhecimento são empresas, universidades e governo.

Empreendedores sociais partem da identificação de um problema e da busca de soluções inovadoras, que não reproduza modelos existentes, comprovadamente ineficazes. Passa-se então à experimentação dessa solução em uma pequena escala. Uma vez que o 
modelo foi testado com sucesso, em geral o empreendedor vai buscar sua expansão, através de sua sistematização e multiplicação. É aí que a solução inovadora ganha escala e pode vir a se tornar um modelo. A contribuição da Ciência da Informação neste contexto passa necessariamente pelo redesenho da formação do profissional que lida com a matéria prima mais importante da Transformação 4.0: a Informação.

Existe uma literatura razoavelmente extensa sobre empreendedorismo, inovação e gestão de tecnologia. É clara a relação entre esses temas, onde o gene dominante é a inovação. Entretanto, de um modo geral, os diversos conceitos sobre o assunto ainda são nebulosos. Como no livro "Verdades Sobre Inovação", publicado pela Comissão Europeia em 1996, encontramos: "o oposto da inovação é o arcaísmo e a rotina". (GLOBAL TALENT, 2012)

Podemos identificar as várias "gradações" da inovação e enumerar sua presença na cronologia da longa jornada de evolução tecnológica. O ponto de inflexão dessa evolução ocorreu em 1637, com a publicação do livro "Discurso sobre o Método" do filósofo e matemático francês René Descartes. Essa obra marca o início do método científico, o pensamento metodológico que possibilitou a passagem do estágio da observação e da lógica para o estágio da experimentação. Nessa metodologia, partindo do nível das ideias e observações, chegamos à experimentação que conduz naturalmente ao desenvolvimento tecnológico. No mundo corporativo a etapa seguinte consiste em levar a tecnologia para o mercado, mediante o uso de modelos de negócio. Essa cadeia de valores, que fornece a metodologia para se passar do nível das ideias para os negócios é o que chamamos de "pipeline" de inovação. Desse ponto de vista, a inovação é o uso de novas ideias para melhorar os processos ou para diferenciar os produtos ou serviços. Portanto, não basta ter novas ideias, elas devem se refletir nos negócios da organização, e na cadeia de valores que leva do universo das ideias ao dos negócios. Gestão da inovação é, na realidade, a gestão desse "pipeline" que envolve ideias, modelos de negócio e mercado. É uma área multidisciplinar e multifuncional que abrange pesquisa e desenvolvimento, planejamento estratégico, produção, operações, marketing e desenvolvimento organizacional.

Quando nos referimos à inovação visando melhorias de processos, diferenciais competitivos ou a diminuição de custos, estamos falando sobre a cadeia de valores que transforma ideias em experimento, que resulta em aplicações associadas a modelos de negócio. Através da inovação, as organizações evoluem, lançam novos produtos, conquistam novos mercados e criam barreiras estratégicas.

A gestão da inovação é fundamental para desenvolver os negócios da organização, e o empreendedor é o elo chave nesse processo. Podemos definir um empreendedor como um gestor da inovação. Ele atua em um amplo espectro que vai da estratégia da inovação à 
estratégia dos negócios. O bom empreendedor não é necessariamente um bom gestor de negócios. A gestão de negócios está relacionada com a qualificação e treinamento nos processos corporativos, enquanto a gestão da inovação exige uma associação do gene da inovação com o dos negócios. É essa conjunção que caracteriza o DNA do empreendedor. O grande desafio do empreendedorismo está em concentrar a área de conhecimento na gestão da inovação e não na gestão do negócio. Como gestor da inovação, o empreendedor está naturalmente associado a empresas emergentes, as chamadas "start-ups". Entretanto, o empreendedor é uma figura essencial para a organização devido à sua visão estratégica da inovação. Mesmo as organizações maduras necessitam do empreendedor para fazer a gestão da inovação, de modo a garantir o seu crescimento e sobrevivência (BAUMOL, 2002).

Em uma economia baseada no capital intelectual e de relacionamento, torna-se fundamental o desenvolvimento de pesquisas que permitam avaliar como a inovação, avanço científico e mudanças tecnológicas contribuem na criação de valor e na determinação de fatores de desempenho - potencial contribuição da Ciência da Informação.

A inovação é a principal alavanca no processo de criação de valor. Em 1942, o economista Joseph Schumpeter captou de maneira eloquente uma das essências da inovação, quando cunhou o termo "destruição criativa". Esse termo incorpora as implacáveis influências e melhorias de inovações anteriores para criar inovações de maior valor. A qualidade cumulativa dessa definição indica que a inovação é o resultado de melhorias contínuas em ambientes relativamente estáveis. Schumpeter também acreditava que as grandes empresas eram os baluartes da inovação, implicando que a inovação é um empreendimento previsível e de baixo risco.

O Hype Cycle Gartner (ou ciclo de hype), Figura 2, Tabela 1, fornece uma representação gráfica da maturidade e adoção das tecnologias e aplicações, além de mostrar com elas vão evoluir ao longo do tempo, ajudando as empresas na tomada de decisão sobre uso e investimento, (MARTINS, 2018).

Figura 2 Gartner Hype Cycle - Ciclo de Vida da Tecnologia

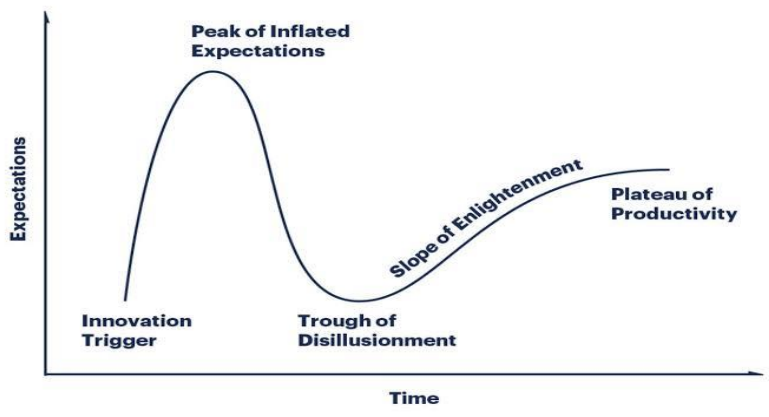

Fonte: GARTNER - TAKE BLOG: Vinicius Martins. 
Tabela 1 Hype Cycle: dividido em cinco fases

1. Innovation Trigger:um potencial avanço tecnológico surge e chama a atenção de todo o mercado. As primeiras provas de conceito ganham muita visibilidade e interesse da mídia. Normalmente, ainda não existem produtos prontos para uso, e a viabilidade comercial ainda não foi provada.

2. Peak of Inflated Expectations: a publicidade antecipada produz uma série de histórias de sucesso - muitas vezes, acompanhadas de dezenas de fracassos. Algumas empresas agem, mas muitas não.

3. Trough of Disillusionment: o interesse diminui à medida que os primeiros testes e implementações não entregam o prometido. Os provedores da tecnologia mudam ou falham. Os investimentos continuam somente se os provedores sobreviventes melhoram seus produtos e entregam valor aos primeiros clientes.

4. Slope of Enlightenment: mais exemplos de como a tecnologia pode beneficiar as empresas começam a surgir e se tornam mais amplamente compreendido por todos. Os provedores de tecnologia lançam novas versões dos produtos. Mais empresas investem em pilotos; empresas conservadoras continuam cautelosas.

5. Plateau of Productivity: a adoção em massa começa a decolar, e os critérios para analisar a viabilidade estão mais claramente definidos. A ampla aplicabilidade e relevância do mercado estão claramente valendo os investimentos.

Fonte: GARTNER - TAKE BLOG: Vinicius Martins.

O trabalho de Clayton Christensen, professor em Harvard, continua de onde Schumpeter parou. Em seu livro de 1997, "O Dilema da Inovação", Christensen postula que as grandes empresas ficam tão envolvidas em atender à base de clientes que já possuem que não conseguem compreender o impacto revolucionário das novas tecnologias em seus mercados. Assim, as tecnologias revolucionárias acabam levando ao deslocamento das grandes empresas. Nos primeiros estágios, o risco é moderado, aumentando radicalmente à medida que a nova tecnologia obtida se estabelece.

Tomando como exemplo o ramo de unidades de armazenagem de informação tal como o disco rígido, Christensen mostra como a maioria das primeiras empresas que dominaram o setor acabou por ser deslocada pelos novos concorrentes. Essas empresas desenvolveram unidades de disco menores, com menos funções, direcionadas a mercados menores não atendidos pelas grandes empresas. Embora fizessem tudo certo para atender aos clientes que já possuíam as grandes empresas não conseguiram avaliar a "trajetória" entre valor e desempenho da tecnologia mais recente. Quando perceberam que a nova tecnologia evoluíra para atender às necessidades do mercado em geral, já era tarde demais. O resultado disso foi que os novos concorrentes derrubaram as grandes empresas dos seus pedestais de domínio do mercado. Ironicamente, muitas dessas "novas grandes empresas" foram da mesma forma, desalojadas pelas ondas subsequentes de novos concorrentes.

O trabalho de Chistensen (1997) destaca uma importante lição. Dedicando-se aos clientes que já possuíam, as grandes empresas enfatizavam a inovação paulatina para melhorar os produtos já fabricados. Portanto, elas tiravam o foco da tecnologia e 
negligenciavam o impacto potencial futuro das novas tecnologias em seus mercados. Em outras palavras, elas não conseguiam desenvolver uma abordagem de diversificação que equilibrasse inovações paulatinas e radicais. Como na tragédia grega, Christensen mostra como essa situação se repetiu em ramos de atividade diferentes entre si, como computadores, equipamentos de escavação, motocicletas e siderurgia.

A Internet leva a visão de Christensen a um ser mais abrangente. Na Internet, empresas menores, com menos capital físico e novos modelos de negócios, podem surgir da noite para o dia em qualquer lugar do mundo. Aprimorando seus negócios centrais e, ao mesmo tempo, estabelecendo parcerias de maneira fluida para ter acesso a conhecimentos complementares, elas ameaçam reconstituir dinamicamente as economias de escopo que antes só podiam ser atingidas por hierarquias maiores.

Existe outro fator na equação da inovação radical: as mudanças radicais nos novos modelos de negócios são precedidas por um evento precursor ou disparador. O telégrafo despedaçou os atrasos associados ao transporte físico da informação. O motor a vapor, o motor de combustão interna e as viagens em aparelhos mais pesados que o ar fizeram surgir, respectivamente, os ramos ferroviário, automotivo e de viagens aéreas. A Internet combina forças tais como alcance global, redução nos custos de transações e maiores retornos de escala, fazendo surgir novos modelos de negócios (DAMAGIO, 2002).

Além disso, outros catalisadores de revoluções estão no horizonte. O mapeamento do genoma humano promete redefinir o ramo farmacêutico e de seguros. A tecnologia de célula a combustível poderá substituir o motor de combustão interna, afetando o ramo petrolífero.

O empreendedorismo em torno da inovação demanda investimentos e uma avaliação do conceito de uma hierarquia entre inovação e valor. Inovações radicais de alto risco, em caso de sucesso, devem obter a maior valorização pelo mercado. Inovações paulatinas previsíveis devem acompanhar valorizações menores. Dois elementos são indispensáveis nessa cadeia: aquele que gera a inovação e o empreendedor que a implementa. (DORNELAS, 2003)

A hierarquia entre inovação e valor apresenta o principal aspecto de uma decisão sobre inovação, gerando questões como: Que tipo de inovação as empresas devem assumir radical ou incremental? Ter a capacidade para atingir o sucesso em inovações incrementais não significa necessariamente a capacidade de dominar inovações radicais. Na verdade, elas estão, frequentemente, em extremos opostos. $\mathrm{Na}$ época do descobrimento do transistor, os especialistas em amplificadores a válvula queriam compactá-las a dimensões milimétricas, onde atualmente cabem milhões destes componentes.

A inovação bem-sucedida leva a uma presença incontestável no mercado que gera um alto valor, além de garantir a sobrevivência em um mercado cada vez mais se uma empresa 
estiver preparada para gerar apenas inovações incrementais, ela não conseguirá gerar as inovações radicais necessárias à reinvenção do seu modelo de negócios. Um dos argumentos centrais é que a inovação bem-sucedida leva à criação de valor.

Na Figura 3 apresentamos as conexões possíveis com a inovação e a criação de valor.

Figura 3Conexões: Ciência da Informação e Inovação

- CIÊNCIA DA INFORMAÇÃo

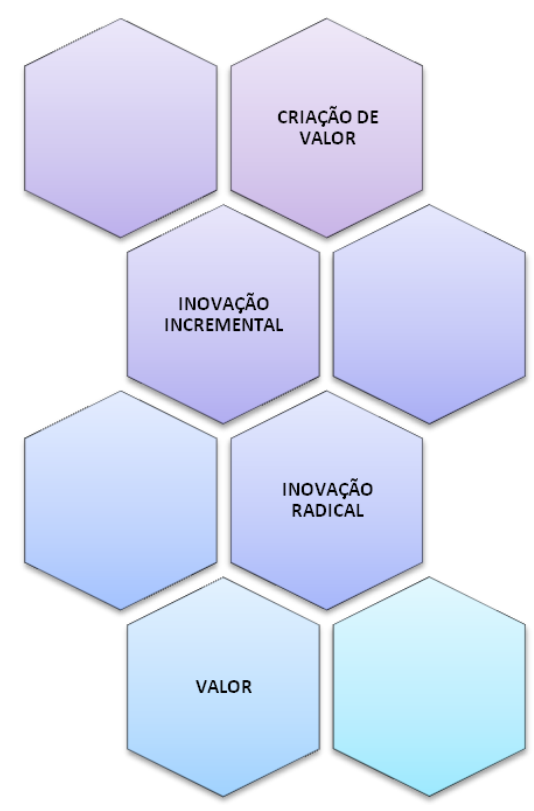

Fonte: Autor

- Inovação Incremental: O refinamento e aprimoramento contínuos de produtos, serviços ou processos existentes dentro de um ambiente competitivo, relativamente estável.

- Inovação Radical: A exploração dedicada de tecnologias emergentes para reinventar radicalmente os ramos de atividade (através de novos modelos de negócios) ou para deslocar produtos ou serviços de grandes empresas em mercados atuais.

- Valor: O valor de mercado de uma empresa de capital ou avaliação de mercado de uma empresa por cotas de responsabilidade limitada.

- Criação de Valor: avaliação entre dois períodos do capital integralizado, mantendo-se constantes todos os outros fatores.

É neste contexto, onde a informação ocupa papel central nas estratégias competitivas das organizações, que se posiciona o Profissional da Informação, com demandas por habilidades e 
competências que o qualifica para atuar em novas áreas da organização e gestão da informação e do conhecimento.

\section{Conclusão}

O Profissional da Informação precisa saber lidar com as demandas e complexidades do mercado de trabalho da era digital e compete à Ciência da Informação encontrar caminhos de inovação nos programas de formação de recursos humanos com habilidades no entorno digital.

A inovação bem-sucedida não cria valor por si mesmo, simplesmente conduz a ele. Como inovação e valor estão ligados entre si? O que leva uma organização a inovar? Economistas como Paul Romer e W. Brian Arthur dão uma elegante resposta capitalista. A inovação é gerada pela sedução do poder semelhante ao do monopólio. Obter uma presença incontestável no mercado, mesmo por um breve período, é o bastante para impulsionar a inovação.

Os esforços para chegar primeiro ao mercado podem ser recompensados pela aceitação de pioneiros fundamentais, o que pode levar ao aumento dos retornos de escala e, potencialmente, a margens mais elevadas para subsidiar a rodada seguinte de inovações. É um ciclo virtuoso que pode reforçar o predomínio no mercado. Esse predomínio, por sua vez, leva as grandes valorizações no mercado. Se a meta for o predomínio, qual é a estratégia?

Em toda a era capitalista, os inovadores bem-sucedidos sempre invocaram variações de uma estratégia em três estágios. Primeiro, eles entram no jogo logo no início. Em segundo lugar, eles expandem agressivamente a sua rede de usuários. Finalmente, eles se dedicam a atividades defensáveis e que agregam valor. A mudança para uma economia em rede está intensificando esses princípios estratégicos. A convergência da economia de rede, a redução dos ciclos de negócios, o aumento dos retornos de escala e as leis da vantagem comparativa estão remodelando a clássica estratégia de três etapas.

As clássicas curvas normais de maturidade de mercado classificam distintamente os compradores em pioneiros na adoção, normais e retardatários. Uma empresa pode optar por representar o papel de líder de mercado, seguidor acelerado ou concorrente atrasado.

Essas convenções funcionam bem em mercados estáveis, com longos ciclos de negócios. Comprima esses ciclos em 18 meses ou menos, e a coisa muda de figura. Apague a categoria dos "retardatários"; os líderes de mercado não terão tempo de cortejá-los. Elimine os concorrentes atrasados; eles perderão cada vez mais a sua presença no mercado para os pioneiros. 
A inovação é uma proposta inerentemente arriscada que exige significativos investimentos adiantados em Pesquisa \& Desenvolvimento ou conquista de clientes. E a aceitação pelo mercado não é garantida. Portanto, não basta simplesmente ser o primeiro a entrar no mercado. O status semelhante ao do monopólio será concedido ao pioneiro que explorar com sucesso as oportunidades de mercado que surgirem. $\mathrm{O}$ concorrente bemsucedido recuperará as despesas iniciais com P\&D ou conquista de clientes e viverá para subsidiar investimentos futuros. Para isso, é fundamental avançar ao segundo estágio da estratégia de inovação: o poder da economia de rede, capaz de criar as condições para comercialização e distribuição dos resultados da inovação. (OCDE, 2005)

$O$ apoio às atividades com uma vantagem intelectual também apresenta duas opções. Primeiramente, elas são umas primeiras linhas de defesa potencial na proteção das suas competências principais. Em segundo lugar, trata-se de áreas de conhecimento que é possível oferecer aos parceiros de negócios para fortalecer o seu relacionamento. Finalmente, o apoio a atividades que não geram vantagem intelectual representa áreas nas quais é importante manter o status quo.

Para a Ciência da Informação, compreender os elos existentes entre a inovação e a criação de valor é essencial para compreender onde a organização começa e termina na economia de rede. Para atingir o sucesso nesse ambiente, é preciso olhar com muita atenção para o espelho corporativo e avaliar, com metodologia, as competências exclusivas que a empresa possui. Conhecendo-as, pode-se determinar onde será agregado valor na economia de rede, através da gestão e organização da informação.

\section{Referências}

AMORÓS, J.; BOSMA. N. GEM - Global Entrepreneurship Monitor 2013 Global Report. Babson: USA, 2014. 104 p.

BAUMOL, W. J. Entrepreneurship, Innovation and Growth: The David-Goliath Symbiosis. Journal of Entrepreneurial Finance and Business Ventures, v. 7, n. 2, p. 1-10, 2002. Disponível em: http://digitalcommons.pepperdine.edu/jef/vol7/iss2/2

CHRISTENSEN, Clayton. The Innovator's Dilemma. Boston: Harvard Business School Press, 1997.

DAGNINO, R.; GOMES, E.; COSTA, G. Gestão estratégica da inovação: metodologias para análise e implementação. Taubaté, SP: Cabral Editora, 2002.

DORNELAS, José. Empreendedorismo corporativo. São Paulo: Editora Campus, 2003.

OECD. Guidelines for collecting and interpreting technological innovation: Oslo Manual. $3^{\text {rd }}$ ed. Paris,2005. 
OECD. Understanding entrepreneurship: developing indicators for international comparisons and assessments. Report on the OECD's Entrepreneurship Indicators Project and Action Plan, May 24, 2006.Paris, 2006.

OECD. Science, Technology and Industry Outlook: Drives of Growth: Information Technology. Innovation and Entrepreneurship. Paris, 2017.

Global Talent 2021. How the new geography of talent will transform human resource strategies. Oxford Economics: OEA, 2012. Disponível em: www.oxfordeconomics.com

MARTINS, V. Hype Cycle Gartner. Takeblog. Disponível em: https://take.net/blog/one-stepbeyond/hype-cycle-gartner-chatbots/ Acessado em: 5 nov. 2019.

MATOS, M., M.et al. GEM - Global Entrepreneurship Monitor-Empreendedorismo no Brasil: 2013. Curitiba : IBQP, 2013. $170 \mathrm{p}$.

Agradecimento FAPESP:PROCESSO 2019/01128-7 